\title{
Effect of Corner Radius and Friction Parameters on the Optimization of the Cold Forging Die Design
}

\author{
A. R. Ab-Kadir \\ School of Mechanical Engineering \\ Universiti Sains Malaysia \\ Engineering Campus, 14300, Nibong Tebal, Pulau Pinang, Malaysia \\ E-mail: ahmad_razlee@yahoo.com \\ A. R. Othman \\ School of Mechanical Engineering \\ Universiti Sains Malaysia \\ Engineering Campus, 14300, Nibong Tebal, Pulau Pinang, Malaysia \\ Z. Samad \\ School of Mechanical Engineering \\ Universiti Sains Malaysia \\ Engineering Campus, 14300, Nibong Tebal, Pulau Pinang, Malaysia \\ Khaleed Hussain. M. T. \\ School of Mechanical Engineering \\ Universiti Sains Malaysia \\ Engineering Campus, 14300, Nibong Tebal, Pulau Pinang, Malaysia \\ A. B. Abdullah \\ School of Mechanical Engineering \\ Universiti Sains Malaysia \\ Engineering Campus, 14300, Nibong Tebal, Pulau Pinang, Malaysia
}

\begin{abstract}
Finite element (FE) method is extensively employed in solving linear and non-linear problems and widely used particularly in analyzing a forming process. It enables the analysis on internal properties such as stress effective, forming load, metal flow and deformation to be performed, in which results in an increase on the performance of forging process. Heading process which is often performed in conjunction with other cold forging process has been simulated by FE-code DEFORM ${ }^{\mathrm{TM}} \mathrm{F} 3 \mathrm{v} 6.0$. The numerical results were analyzed to evaluate the effect of the fillet size and the friction value on the cold heading process. It was found that the heading process provided good precision and productivity as the size of fillet was increased; due to intensification of the metal flow to infuse the die cavity. On the other hand, the friction value also played an important role in governing the reaction force between workpiece and punch in the process.
\end{abstract}

Keywords: Finite element method, Cold forging, Forming load, Friction coefficient, DEFORM

\section{Introduction}

\subsection{Forging Process}

Cold forging is an essential process and widely used in a typical manufacturing production. In the process, the metal is continuously pressed under high pressure into high strength parts and as a result, the material experienced extensive plastic deformation during the progression. Normally, it is used to produce mass production of mechanical components such as connecting rods, bolts, screw, nut, universal joint and many others. In comparison to another processes such as 
casting and machining, cold forging has many advantages. One of them is maximizing the material properties in the finished part. In the process, the grain structure of the material is rearranged to follow the contour of the component and hence, increases the strength of the component. On the other hand, cutting process would cause damages to the grain structure and therefore, the properties of the part become inferior to the initial workpiece from which it was. In addition, the extrusion operation could also cause the metal to flow only along the axis of the workpiece, hence reduces the mechanical performance in the transverse direction. Besides, cold forging has a high performance on the production rate and repeatability. The parts with cold forging process are largely produced at high rate compare to those achieved by the machining processes as the parts are immediately ready for use after the forging; the process is conducted by automated production lines that directly converts the workpiece to the finished parts. The repeatability of the process becomes excellent with optimal die design, low temperature and optimal lubrication (Ngaile, G., Saiki, H., Ruan, L. and Marumo, Y. 2007.). Another important advantage of cold forging process is the amount of waste material for finished part is very insignificant. The process is a "chipless machining", in which sometimes requires less or no cutting process as well as eliminates secondary grinding.

\subsection{Computer-Aided Engineering Technology}

In general, it has been concluded that the major variables involved in forging process includes workpieces properties and geometry, tools properties and geometry, interface condition between tool and workpiece, environmental conditions, forging machining (force, velocity and direction of tool movement), and mechanics of the deformation zone (Ko, D. C., Kim, D. H. and Kim, B. M. 1999.)( Altan, T., Ngaile, G. and Shen, G. 2005.). However, these critical issues are very difficult to address during the real-time forging process. Computer-aided engineering (CAE) code is perhaps, the best tool in order to generate, validate, verify and optimize the design solutions before they are implemented in the process (Kobayashi, S., Oh, S. I. and Altan T. 1989.). The CAE enables the analysis of the design of forming process, material selection, tooling structure, properties configuration and quality of the product to be performed. CAE codes with finite element method permits simulation of the system in solving linear and non-linear problems and is widely used in manufacturing including the forging process. Furthermore, it is also able to evaluate the internal properties such as stress effectives, forming load, strain distribution, deformation and temperature distribution.

Santos et al (Santos, A. D., Duarte, J. F., Reis, A., Rocha, B., Neto, R. and Paiva, R. 2001.) utilized the FE method to determine the size of initial material of workpieces and the forces that to be implemented. The authors have been discussed that the numerical simulation could in fact assist modification and hence reduce trial and error stage in preparing the tools for forming process. FE method may also provide an important answer in predicting the process and defects. Jun et al (Jun, B. Y., Kang, S. M., Lee, M. C., Park, R. H. and Joun, M. S. 2007.) presented a powerful approach in estimating the geometry of cold forging part by using FE codes by analyzing the die structure and springback characteristics of the workpiece. Lee et al (Jun, B. Y., Kang, S. M., Lee, M. C., Park, R. H. and Joun, M. S. 2002.) have performed a study to evaluate the dimensional differences between forged components and forging die by using FE method as well as experimental data. In numerical simulation with a commercial FE code of DEFORM-2D ${ }^{\mathrm{TM}}$, two different approaches have been discussed comprehensively for comparison with the measured elastic strains. On the other hand, Chen et al (Chen, X., Balendra R. and Qin, Y. 2004.) presented the least square approach in order to minimize the component mistake with regards to the die-elasticity, springback, secondary yielding and temperature variations. In order to clearly illustrate the approach, an axisymmetric closed-die forging has been employed. Also, $\mathrm{Wu}$ and Hsu (Wu, C. Y. and Hsu, Y. C. 2002.) have analyzed the influence of die shapes with different fillet radii and draft angles on the extrusion process. In addition, they performed comparisons between the prediction of finite element method and experimental results of the respective deformation mode in reference to the parameters of flow condition, the flange width, the boss height, as well as load and strain distributions.

Proper lubrication is extremely important to the completion of heading process of stainless steels, high temperature alloys or other specialty metals. It was found that a basic knowledge of lubrications could prevent subsequent fabrication difficulties like tooling failure, galling, wear or die seizing (Schey, J. A. 1983.). As the heading processes, which include upsetting and forming or a combination of operation, require high pressure application that generates high temperature elevations due to tremendous external and internal friction, lubricant helps to reduce friction in heading operation by providing a film that prevents metal-to-metal contact. Subsequently, friction is an undesired factor which has to be reduced in order to have low forming load, low stress and deformation distribution on die as well as better product quality. In addition, combination lubrications are essential for heading process as greater pressure produces higher heat and friction, hence results in rapid breakdown of the coating.

On the other hand, in cold forging process, die design parameters such as size of fillet corner, draft angel, flash geometry and die surface contact area may influence die wear and hence, the fatigue life. Corner and fillet radii are vital in die design in order to allow preclusion of defects in the product as well as to prolong the die life. For an instance, results of an analysis provide stress concentration and deformation data on die that are depended on the geometry of the die, in which the stresses are redistributed over an area. Commonly, early failure occurs due to excessive stresses which 
are concentrated in a sharp corner of the die. In addition, it was anticipated that the size of radii will greatly affect the die filling state as well as the forming load taking into account the quality of forged part.

In this paper, an approach to evaluate an optimal size of corner fillet in cold forging die design as well as an optimal combination of lubrications to employ in cold heading process are presented. Die stress and deformation analyses are carried out to analyze the effect of different sizes of fillet and different friction coefficient values. The optimal size of fillet and friction coefficient is assessed with the value of die stress and forming load, respectively. The CAD models are incorporated in CAE simulation by using FE codes in order to identify the stress and deformation distributions on punch as well as to determine the respective forming load.

\section{Methodology}

The diagram shown in Figure 1 represents a methodology framework of CAE simulation for forging process and tool analysis. It showed that the CAD models for process simulation were created in different platforms and subsequently were transferred into FE codes via data exchange platforms such as STEP, IGES or STL. In the present study, the workpiece, punch, bottom die and die assembly components were constructed in the CAD models before the commercial FEM-code DEFORM ${ }^{\mathrm{TM}}$ F3 v6.0 was implemented via CAE platforms to establish the simulation. In the CAE platform, a number of parameters were specified including the process control and constraints, re-meshing control and criteria, boundary condition, and the loading step before conducting the die stress and deformation analysis.

During FE simulation, there are possibilities for the computational error to take place due to large displacement and deformation. Since, the relative movement between the deforming materials and die surface is very significant, computation with a Lagrangian mesh is difficult in accommodating the changes in deformation of one mesh system as well as the complexity in combining the die boundary profile into FE mesh with increasing relative deformation. In order to overcome these problems, it is necessary periodically to apply remeshing algorithm into the system. The remeshing involved two procedures; first, was the integration of new mesh into the workpiece, and second, was the relocation of information from old to the new mesh. A commercially available mesh generator was utilized in order to generate the new mesh scheme that was essentially the same as the initial mesh generation.

On the other hand, the boundary surface, $S$ can be written in three distinct parts as the following.

$S=S_{u}+S_{F}+S_{c}$

Where $S_{c}$ is the boundary condition along the workpiece-tool interface, $S_{u}$ is the velocity boundary condition and $S_{F}$ is the traction boundary condition. In the algorithm, $S_{u}$ enforced the velocity condition only at nodes, in which velocities of elements and nodes shape function were determined along the element-side. With respect to the node velocity component, the first derivative of $\pi_{\mathrm{SF}}$ is recalled and hence, the imposition of the traction boundary condition on $S_{F}$ would be straightforward. Subsequently, the traction boundary condition was imposed in the form of nodal-point forces. On the surface $S_{u}$, the velocity was prescribed in the normal direction to the interface and on the other hand, the traction was prescribed in the tangential direction.

In addition, the process parameters such as friction coefficient value, movement of die, workpiece and die temperature and the positioning the object between workpiece and die have also to be defined. The simulation results, which included forming forces, stress and deformation distributions as well as metal flow, were considered in order to analyze the effect of the corner radius and the friction value on forging process. Therefore, the optimal size of fillet and the friction coefficient value were configured in order to enhance the performance of forging process.

\subsection{Computational Simulation of Cold Forging Process}

Fastener manufacturing process is one of the cold forging processes and is also known as cold heading. The process involves applying a force through a punch to the end of a workpiece contained in a die. In order for the workpiece to experience a plastic flow, the applied force should exceed the elastic limit of the metal. Typically, the heading process is often performed in conjunction with other cold forging process, in which consists of two or three different operations; i.e. one or two performing method and one finishing process. The principal stages of the cold heading process of fastener, simulated by FEM-code DEFORM ${ }^{\mathrm{TM}} \mathrm{F} 3 \mathrm{v} 6.0$, are shown in Figure 2. The operation consisted of a performing process followed by the head compression. Extensive study for die stress analyses was performed in the area of the latter stage to determine the stresses and deformations on the punch. Figure 3 shows the final geometry of workpiece obtained in the simulation, in which was similar to actual fastener geometry.

Table 1 lists the mechanical and physical properties of the model. On the other hand, two different analyses were implemented for the FE study and were specified in Table 2. In the study to determine the optimal friction coefficients for the process, four different types of lubricants were utilized on the die punch. Lub 1 contained the metal soap (calcium and sodium) and chemically combined with chlorine and fluorine. On the other hand, Lub 2 and Lub 3 were restricted to only a metal soap (calcium and sodium) but the percentage of calcium in the latter was more than the former. The final parameter, Lub 4 was a combination of zinc phosphate coating and metal soap that is commonly used 
for cold forging and its friction coefficient was 0.1. Note that, the friction coefficient value for Lub 1, Lub 2 and Lub 3 were specified as $0.4,0.12$ and 0.14 , respectively.

The geometric dimension of the punch is highlighted in Figure 4 and $\mathrm{Rp}$ denotes the fillet location which presumably would affect the forming load and die filling. The computational model provided the material flow of the cold heading process, in which exhibited an informative grid distortion pattern. Therefore, Figure 5 highlights the grid pattern obtained from process modeling output at $30 \%, 60 \%$ and $95 \%$ of material reductions. It demonstrated the significance of the metallurgical properties in the process of cold heading in achieving superior finished part. It was found that along the axis of the blank of the metal flow, the grain structure was rearranged during the operation to the contour of the part and this new grain structure apparently supported the parts and added the strength to bolt head. This unique property provided an advantage to the cold forging; the grain flow lines established by the various cold forming process remain uninterrupted in the finished part and the grain structures were appeared finer than in hot-forged parts.

\section{Results and Discussion}

\subsection{FE results of different sizes of fillet}

Results of the FE analyses for different sizes of fillet were comprehensively discussed. Figure 6 denotes the final filling state of the punch for various fillets. It was found that the material was unable to fill in the punch cavity for the case of $\mathrm{Rp}=1.0 \mathrm{~mm}$ and $1.5 \mathrm{~mm}$, whilst the punch-filling state was attained when Rp equal or more than $2.0 \mathrm{~mm}$. If the size of fillet was too small $(<2.0 \mathrm{~mm})$, it prevented the material to effectively switch to the side wards of die cavity due to the centrifugal flow which was attributed to compression of the cylindrical workpiece. As a result, the unfilled area was simultaneously trapped at the die corner. Therefore, the precision and productivity of forging process were very much depending on the geometry of the die; it was found that the size of die corner affected the metal flow of the workpiece. The forging process provided good precision and productivity when the size of fillet increases, as the metal was able to flow easily to fill in the die cavity.

It was observed that the fillet of $1.0 \mathrm{~mm}$ produced a very low precision of the final product and unfilled state. Figure 7 shows that the maximum forming load increased with the size of fillet as the punch progressed for the full die-filling state. The values of the maximum load exhibited by $1.0 \mathrm{~mm}, 1.5 \mathrm{~mm}, 2.0 \mathrm{~mm}$, and $2.5 \mathrm{~mm}$ fillets were $457 \mathrm{kN}, 440 \mathrm{kN}$, $427 \mathrm{kN}$ and $400 \mathrm{kN}$, respectively. This was attributed to the continuously increasing load in the final forming operation in order to fill the die corners. Accordingly, the largest size of fillet only required the lowest forming load rather than those of the smaller sizes.

According to Figure 8, it certified that the permanent displacement was not proportional to the size of fillet, but increased as the size of fillet decreased. The highest and lowest values for the permanent displacement were attained as $0.0702 \mathrm{~mm}$ and $0.0662 \mathrm{~mm}$ when $\mathrm{Rp}$ were $0.1 \mathrm{~mm}$ and $2.5 \mathrm{~mm}$, respectively. In addition, by referring to Figure 9 , it shows that the highest value for maximum stress was $1600 \mathrm{MPa}$ when $\mathrm{Rp}$ was at $0.1 \mathrm{~mm}$ and the lowest value for maximum stress was $1450 \mathrm{MPa}$ as $\mathrm{Rp}$ approached $2.5 \mathrm{~mm}$. significantly, the maximum stresses were observed at the corner of the punch, but not at the top surface. It was observed that the metal flow was mainly influenced by the tool geometry, in which provided the effects to the force constraints of the process, stress concentration and permanent displacement on the tool. Furthermore, it was observed that the geometry of the tool influenced the deformation of the workpieces, given that the fillet corner increased, die wear would decrease and hence the fatigue life increased, since a small corner would introduce high stress concentration and permanent displacement. Subsequently, it was suggested from this study that the optimal size of the corner radius for the punch design should equal or more than $2.0 \mathrm{~mm}$ in order to achieve superior quality of finished parts.

\subsection{FE results of different types of lubricant}

By referring to Figure 10; it indicates that the total forming load was increased with the values of friction coefficient. The highest maximum forming load was produced when Lub 1, which has the highest friction coefficient value, was employed. On the other hand, the lowest maximum forming load was generated as Lub 4 was applied on the punch. It was found that the forming load values exhibited by Lub 1, Lub 2, Lub 3, and Lub 4 were $675 \mathrm{kN}, 510 \mathrm{kN}, 542 \mathrm{kN}$ and $489 \mathrm{kN}$, respectively. It has been evaluated from the FE results that the forming load was found to be proportional to the friction coefficients, as the friction values increased, the die life decreased as higher friction coefficients required higher load to fill the die cavity. On the other hand, it was observed that for the minimum value of friction coefficient, the workpiece deformed almost uniformly, but when the maximum value of friction was present, the deformation of the workpiece was found inconsistent. Based on the analyses, the friction utilized in the die design to a great extent influenced the metal flow as well as the reaction force between the workpiece and the punch in the forging process. It was noticed that the metal flow was unable to effectively fill the die cavity as those of the friction value has increased.

In addition, it was indicated in Figure 11 that the permanent displacement also increased with friction coefficients. The lowest permanent displacement was $0.0771 \mathrm{~mm}$ with the friction coefficient approached 0.1 for Lub 4. Also, from Figure 12, it shows that the stress value has increased as the friction coefficient intensified, in which an increase in die 
wear was evaluated and hence, the fatigue life would be reduced. From the analysis, the highest maximum stress was found as $1550 \mathrm{MPa}$ with friction coefficient of 0.4 for Lub 1, whilst the lowest value of maximum stress on the punch was $1390 \mathrm{MPa}$ with friction coefficient value of 0.1 for Lub 4 . Note that, Lub 4 was a high lubricity material that was capable to reduce considerably the sliding friction between the punch and the workpiece. Therefore, the workpiece would deform with ease in order to fill the die cavity and hence decreasing the permanent displacement at punch. Subsequently, the stress concentration at punch would be decreased, in which the die wear was reduced accordingly with the fatigue life increased. In addition, the erosion of the punch surface would be reduced as Lub 4 has the high characteristic of non-abrasive. In summary, it was suggested that the optimal value of friction coefficient in cold forging operation was 0.1 , in which the lubricant consisted of zinc phosphate coating and metal soap combination (calcium + sodium).

\section{Conclusions}

Computer-aided engineering (CAE) simulation is a useful tool to optimize, validate, verify and hence, generate the design solutions before they are implemented. The results can be utilized to analyze the tool design and forming processes during the designing stage as well as in the trouble shooting stage. In the current study, the effects of corner radius and friction coefficients were studied on the optimization of the cold forging die design. Workpiece and die assembly components were constructed in the CAD models before the commercial FEM-code DEFORM ${ }^{\mathrm{TM}}$ F3 v6.0 was implemented via CAE platforms in order to establish the cold heading process of fastener.

It was found that the precision and productivity of forging process were very much depending on the geometry of the die; the size of die corner affected the metal flow of the workpiece. It was observed that the geometry of the tool influenced the deformation of the workpieces, given that the fillet corner increased, die wear would decrease and hence the fatigue life increased, since a small corner would introduce high stress concentration and permanent displacement. In addition, it was concluded that the forging process provided good precision and productivity when the size of fillet increases, as the metal was able to flow easily to fill in the die cavity. Subsequently, it was suggested that the optimal size of the corner radius for the punch design should be equal or more than $2.0 \mathrm{~mm}$ in order to achieve superior quality of the finished parts.

It has been evaluated from the FE results that the forming load was found to be proportional to the friction coefficients, as the friction values increased, the die life decreased as higher friction coefficients required higher load to fill the die cavity. On the other hand, it was observed that for the minimum value of friction coefficient, the workpiece deformed almost uniformly, but when the maximum value of friction was present, the deformation of the workpiece was found inconsistent. Based on the analyses, it was concluded that the optimal value of friction coefficient in cold forging operation is 0.1 , in which the lubricant consisted of zinc phosphate coating and metal soap combination (calcium + sodium).

\section{References}

Altan, T., Ngaile, G. and Shen, G. (2005). 'Cold and hot forging fundamentals and applications'; ASM International the Materials Information Society;

Chen, X., Balendra R. and Qin, Y. (2004). 'A new approach for the optimization of the shrink-fitting of cold-forging dies', J. Mater. Process. Technol. 145, 215-223.

Jun, B. Y., Kang, S. M. Lee, M. C. Park, R. H. and Joun, M. S. (2007). 'Prediction of geometric dimensions for cold forgings using the finite element method', J. Mater. Process. Technol. 189, 459-463.

Ko, D. C., Kim, D. H. and Kim, B. M(1999). 'Application of artificial neural network and Taguchi method to perform design in metal forming considering workability'; Int. J. Mach. Tools Manufact. Volume 39, Issue 5, 771-785.

Kobayashi, S., Oh, S. I. and Altan T. (1989). 'Metal forming and the finite element method'. New York: Oxford University Press.

Lee, Y., Lee, J. and Ishikawa, T. (2002). 'Analysis of the elastic characteristic at forging die for the cold forged dimensional accuracy’, J. Mater. Process. Technol. 130, 532-539.

Ngaile, G., Saiki, H., Ruan, L. and Marumo, Y. (2007). 'A tribo-testing method for high performance cold forging lubrications'; WEAR, 262, 684-692.

Santos, A. D., Duarte, J. F., Reis, A.; Rocha, B., Neto, R. and Paiva, R. (2001). 'The use of finite element simulation for optimization of metal forming and tool design', J. Mater. Process. Technol. 119, 152-157.

Schey, J. A. (1983). 'Tribology in Metalworking, Friction, Lubrication and Wear', American Society for Metals.

Wu, C. Y. and Hsu, Y. C. (2002). 'The influence of die shape on the flow deformation of extrusion forging', J. Mater. Process. Technol. 124, 67-76. 
Table 1. Mechanical and physical properties employed in the analysis

\begin{tabular}{lc}
\hline Items & Forging Conditions \\
\hline Die material & AISI-D2 \\
\hline Poison ratio, $\boldsymbol{v}$ & 0.3 \\
\hline Model of die & Plastic \\
\hline Friction coefficient, $\boldsymbol{\mu}$ & 0.12 \\
\hline Workpiece material & SS 302 \\
\hline Model of workpiece & Plastic \\
\hline Initial temperature of & \\
\hline workpiece & $25^{\circ} \mathrm{C}$ \\
\hline Initial temperature of die & \\
\hline Number of mesh & \\
\hline
\end{tabular}

Table 2. Two different analyses implemented for the FE simulation

\begin{tabular}{|c|c|}
\hline $\begin{array}{l}\text { Different fillet size at } \\
\text { second punch, } R_{p}\end{array}$ & $1.0 \mathrm{~mm}, 1.5 \mathrm{~mm}, 2.0 \mathrm{~mm}, 2.5 \mathrm{~mm}$ \\
\hline \multicolumn{2}{|l|}{ ubricant types } \\
\hline Lub 1 & Calcium, sodium, chlorine, fluorine $(\mu=0.40)$ \\
\hline Lub 2 & Calcium and sodium soap $(\mu=0.12)$ \\
\hline Lub 3 & Calcium and sodium soap (higher $\mathrm{Ca} \%$ than $\mathrm{Lub} 2, \mu=0.14$ ) \\
\hline Lub 4 & Zinc phosphate coating + metal soap $($ calcium + sodium, $\mu=0.10)$ \\
\hline
\end{tabular}




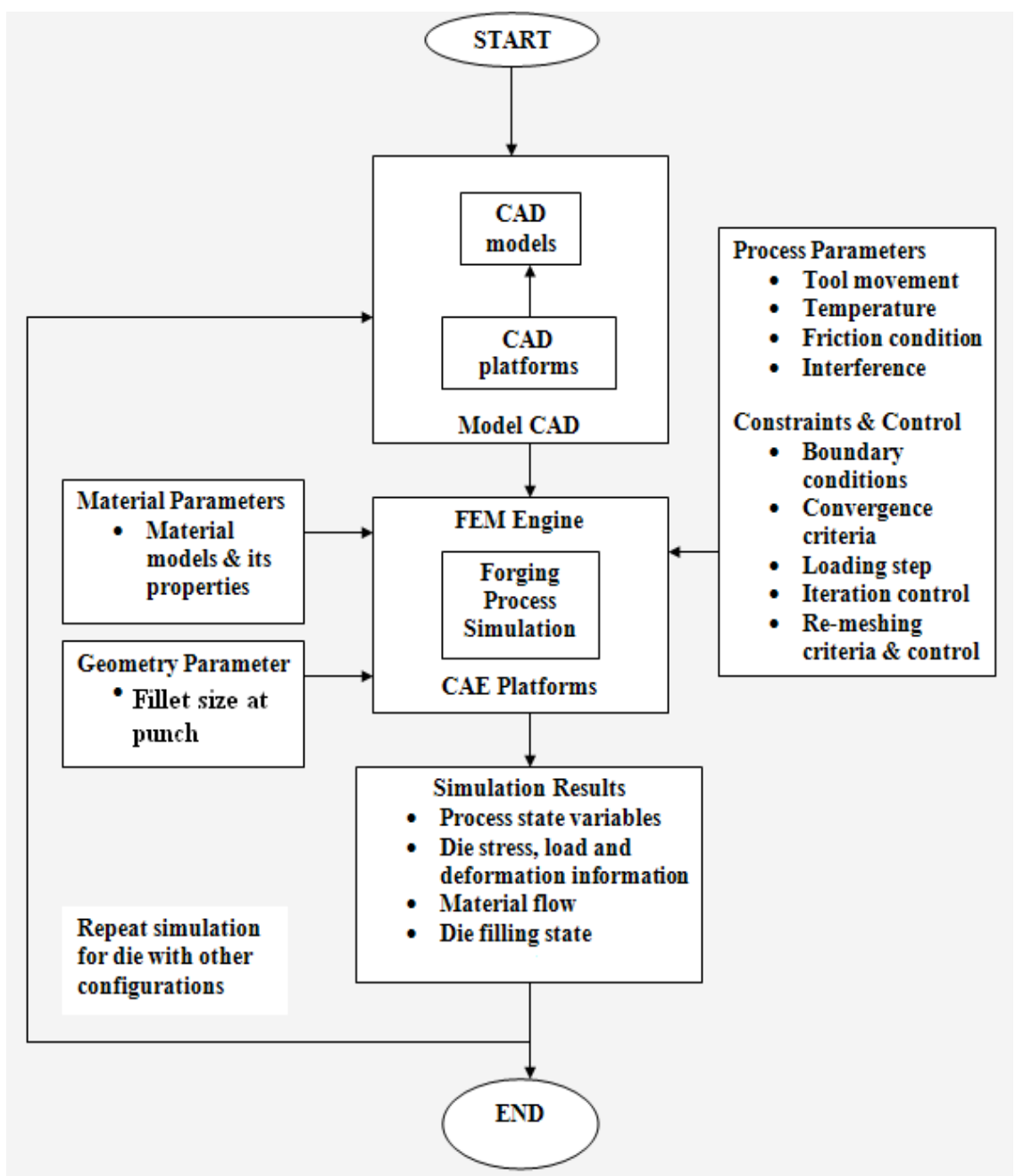

Figure 1. Methodology framework

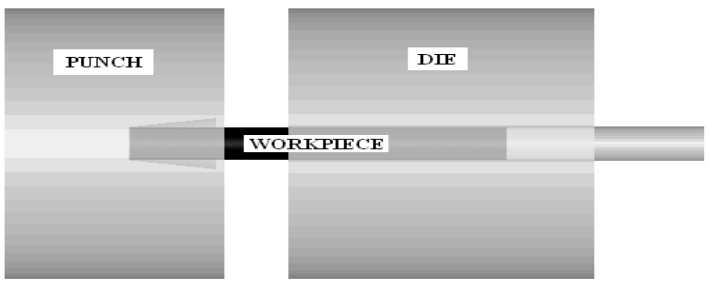

a) The position of punch prior to the cold forging process

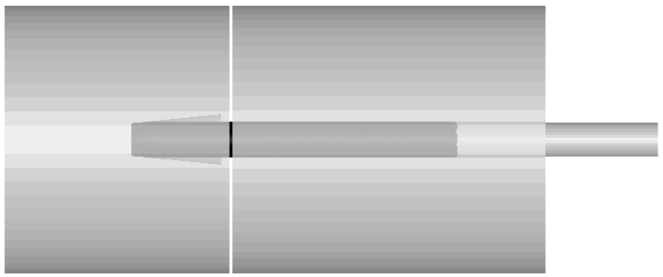

b) Pre-forming operation (First stroke) 


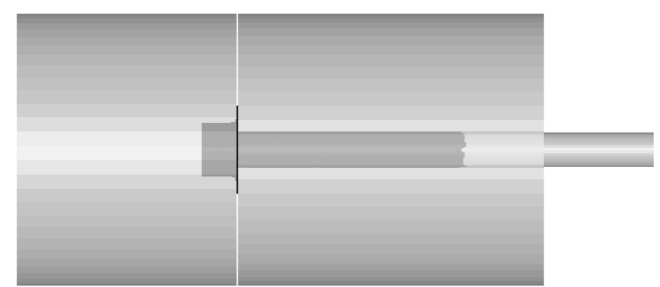

c) Heading compression (Final stroke)

Figure 2. The forming stages of cold heading process of fastener

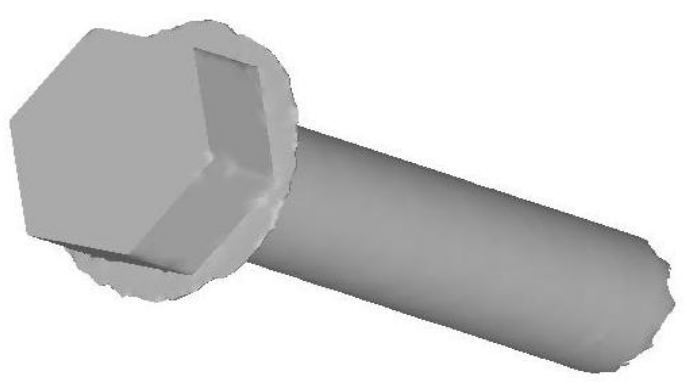

Figure 3. Isometric view of fully deformed workpiece

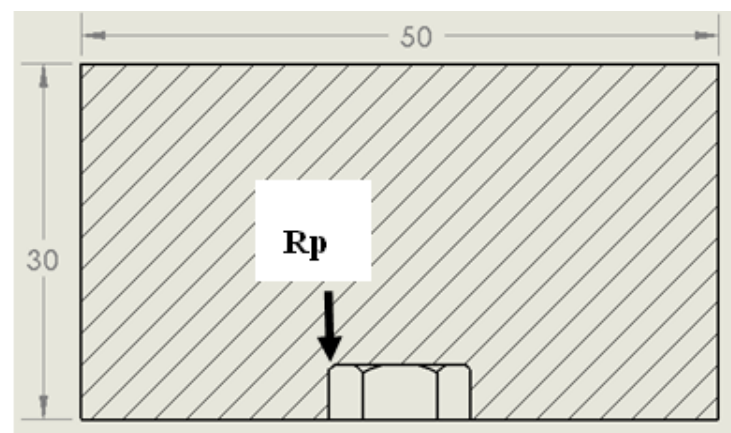

Figure 4. Geometric dimension of the second punch and Rp denotes the fillet at corner of punch
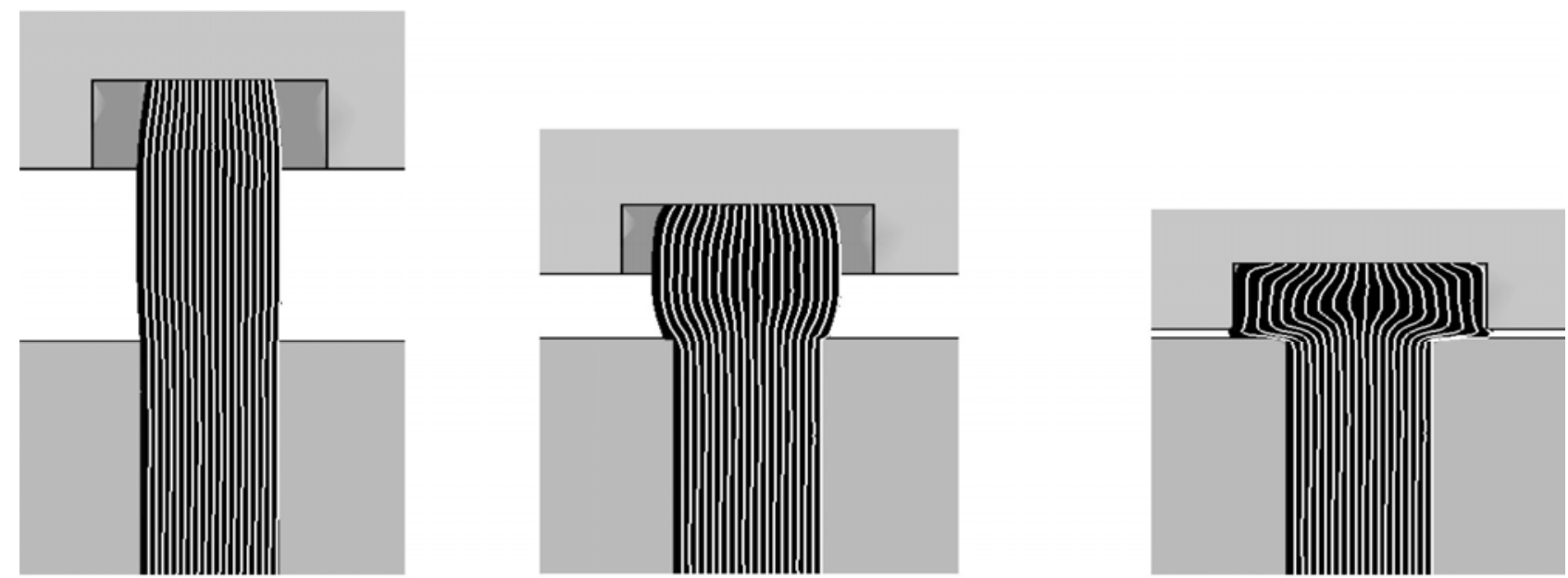

Figure 5. Computational simulation of material flow in heading at 30\% reduction, $60 \%$ reduction and $95 \%$ reduction. 


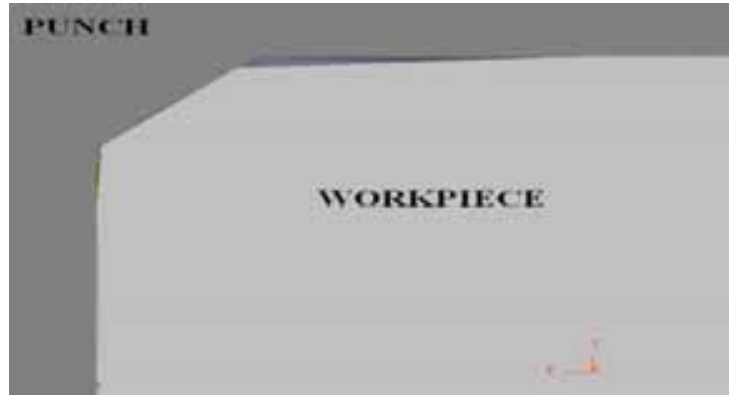

(a) $\mathrm{Rp}=1.0 \mathrm{~mm}$

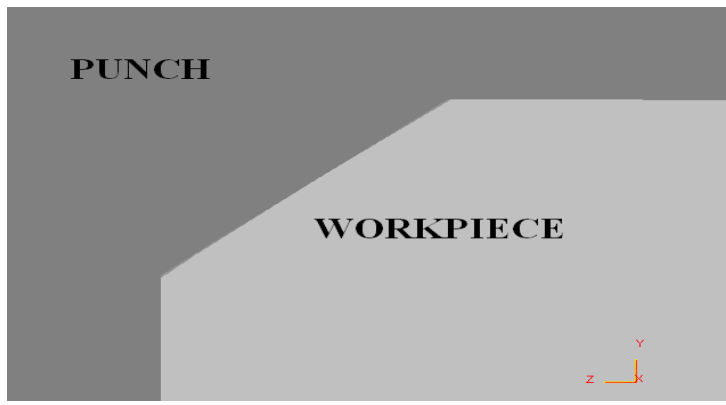

(c) $\mathrm{Rp}=2.0 \mathrm{~mm}$

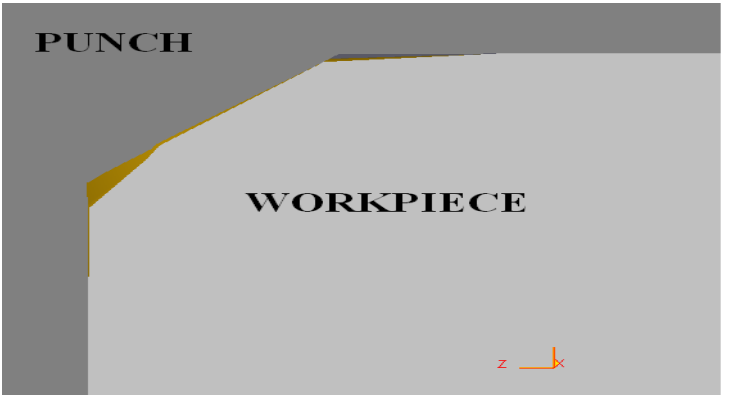

(b) $\mathrm{Rp}=1.5 \mathrm{~mm}$

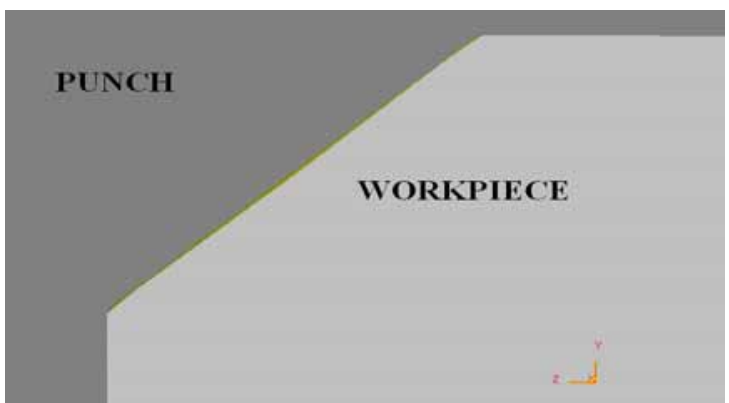

(d) $\mathrm{Rp}=2.5 \mathrm{~mm}$

Figure 6. The final filling states of the punch for various fillet sizes

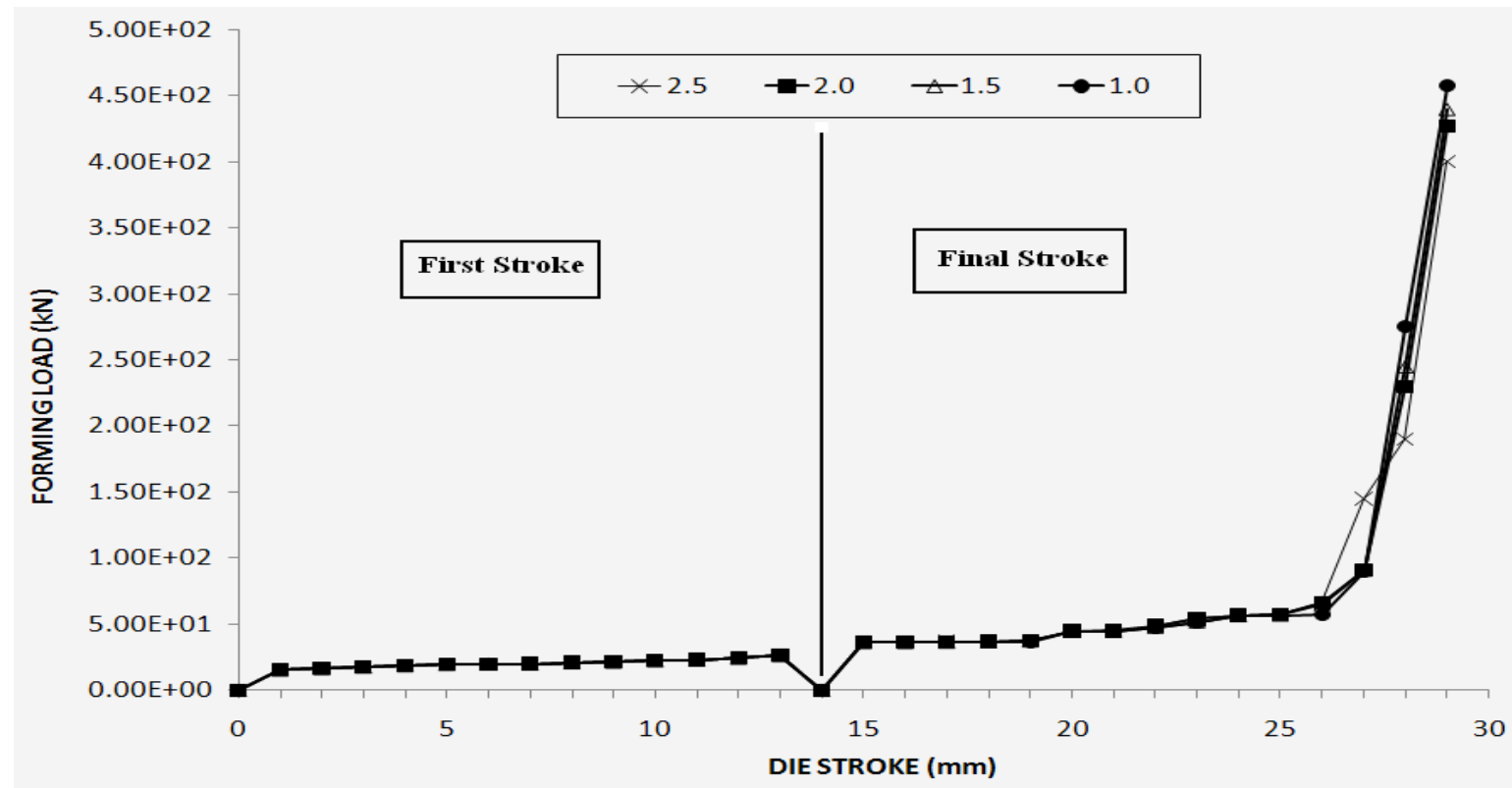

Figure 7. Forming load vs. die stroke curves for various Rp 


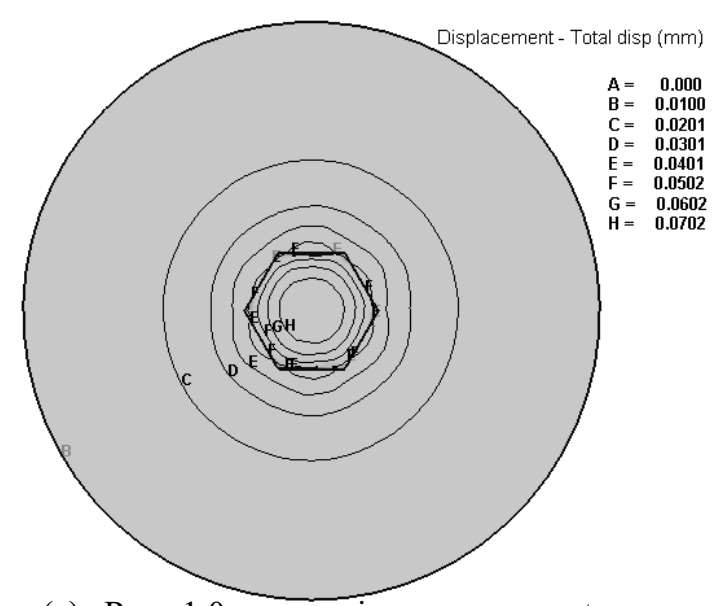

(a) $\mathrm{Rp}=1.0 \mathrm{~mm}$; maximum permanent displacement $=0.0702 \mathrm{~mm}$

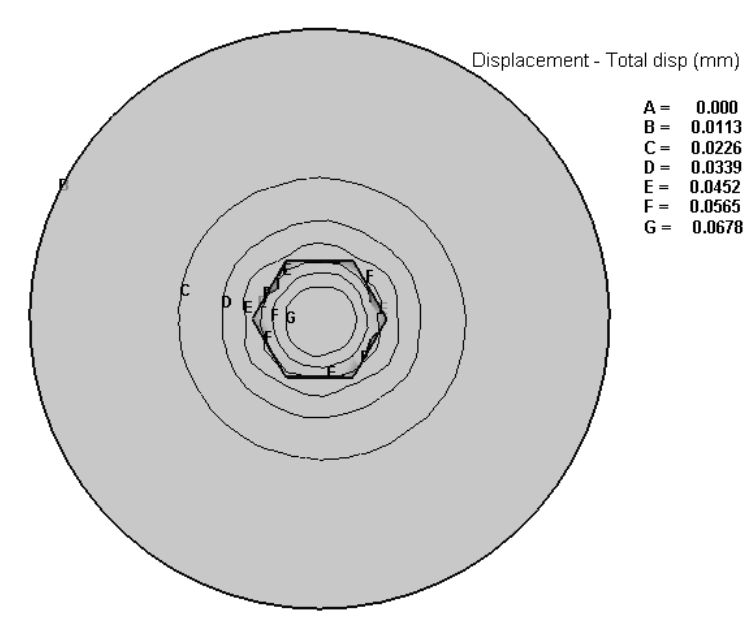

(c) $\mathrm{Rp}=2.0 \mathrm{~mm}$; maximum permanent displacement $=0.0678 \mathrm{~mm}$

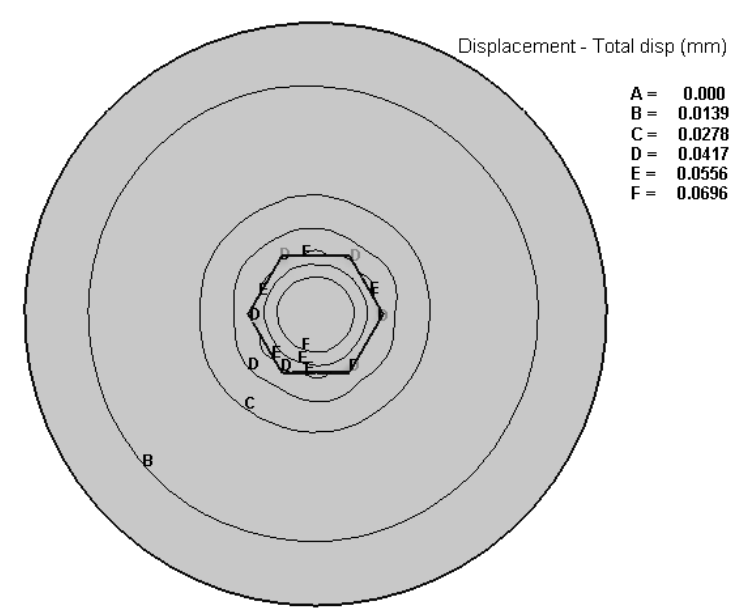

(b) $\mathrm{Rp}=1.5 \mathrm{~mm}$; maximum permanent displacement $=0.0696 \mathrm{~mm}$

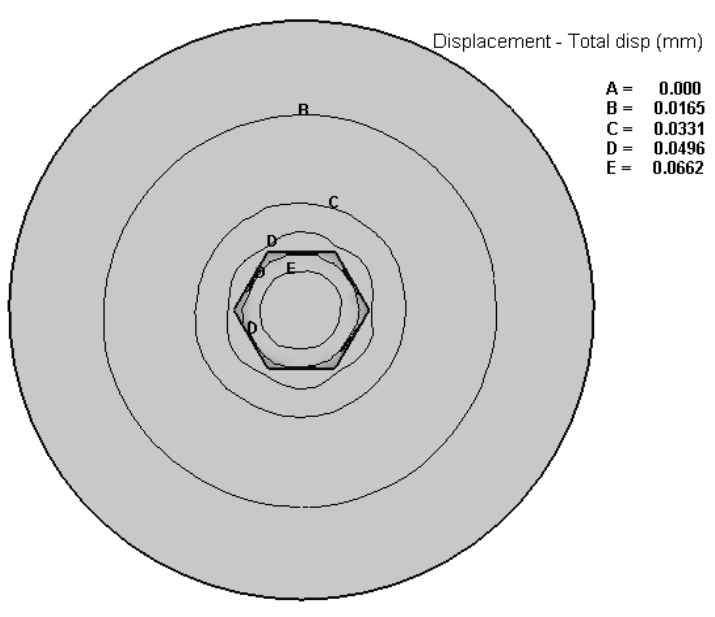

(d) $\mathrm{Rp}=2.5 \mathrm{~mm}$; maximum permanent displacement $=0.0662 \mathrm{~mm}$

Figure 8. Tool permanent displacement at second punch evaluated by finite element method for different sizes of corner fillet. 


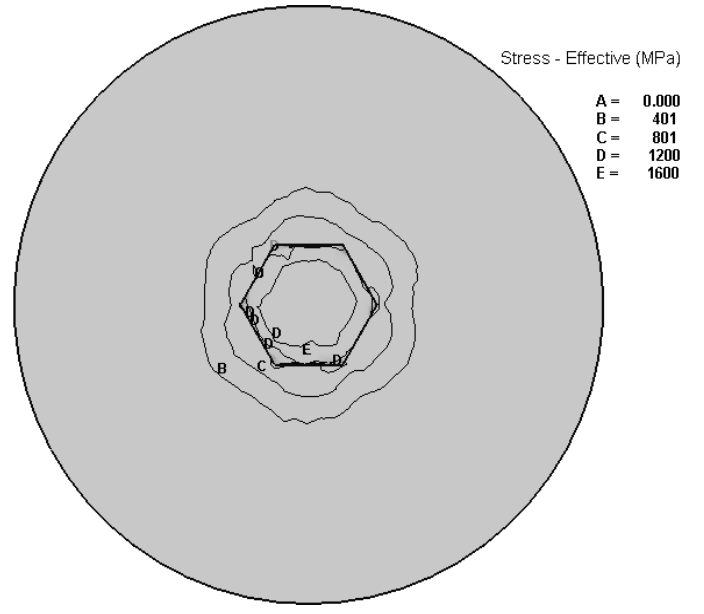

(a) $\mathrm{Rp}=1.0 \mathrm{~mm}$;

maximum stress $=1600 \mathrm{MPa}$

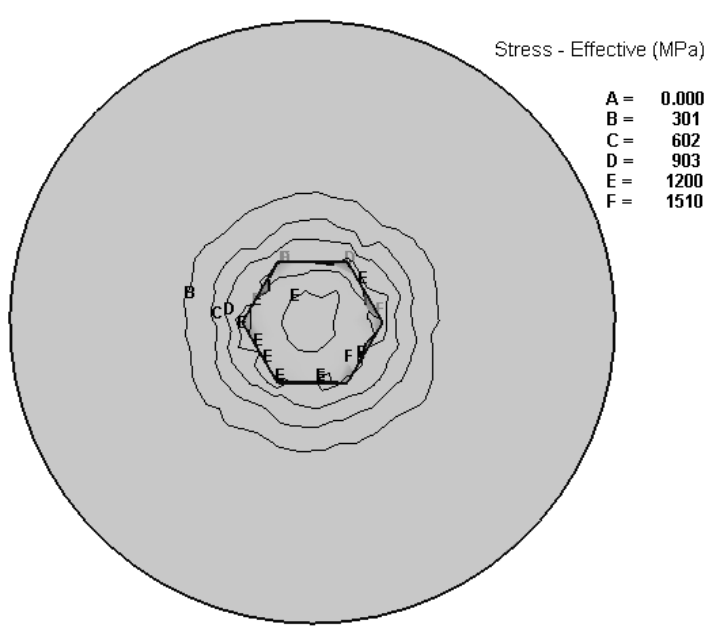

(c) $\mathrm{Rp}=2.0 \mathrm{~mm}$;

maximum stress $\quad=1510 \mathrm{MPa}$

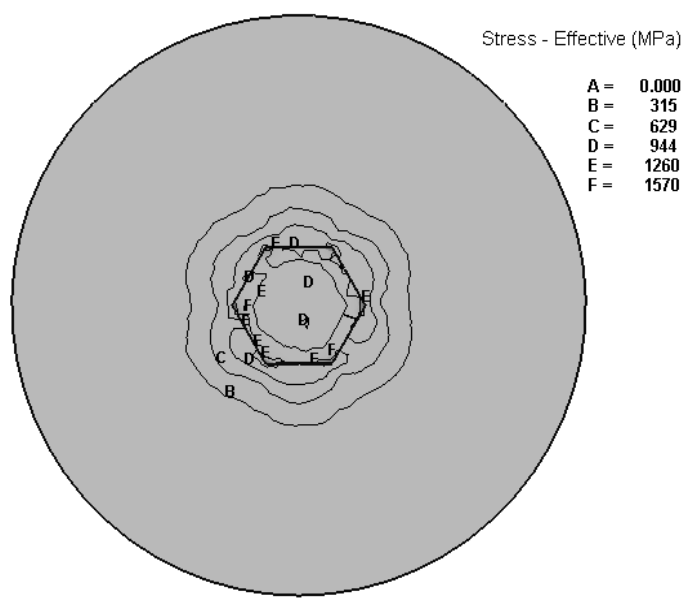

(b) $\mathrm{Rp}=1.5 \mathrm{~mm}$;

maximum stress $=1570 \mathrm{MPa}$

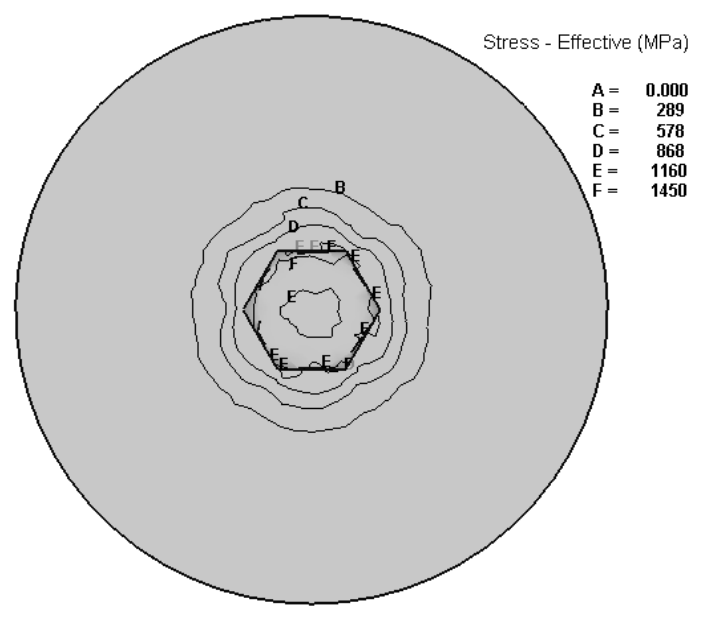

(d) $\mathrm{Rp}=2.5 \mathrm{~mm}$;

maximum stress $=1450 \mathrm{MPa}$

Figure 9. Tool stress contour at second punch evaluated by finite element method for different sizes of corner fillet. 


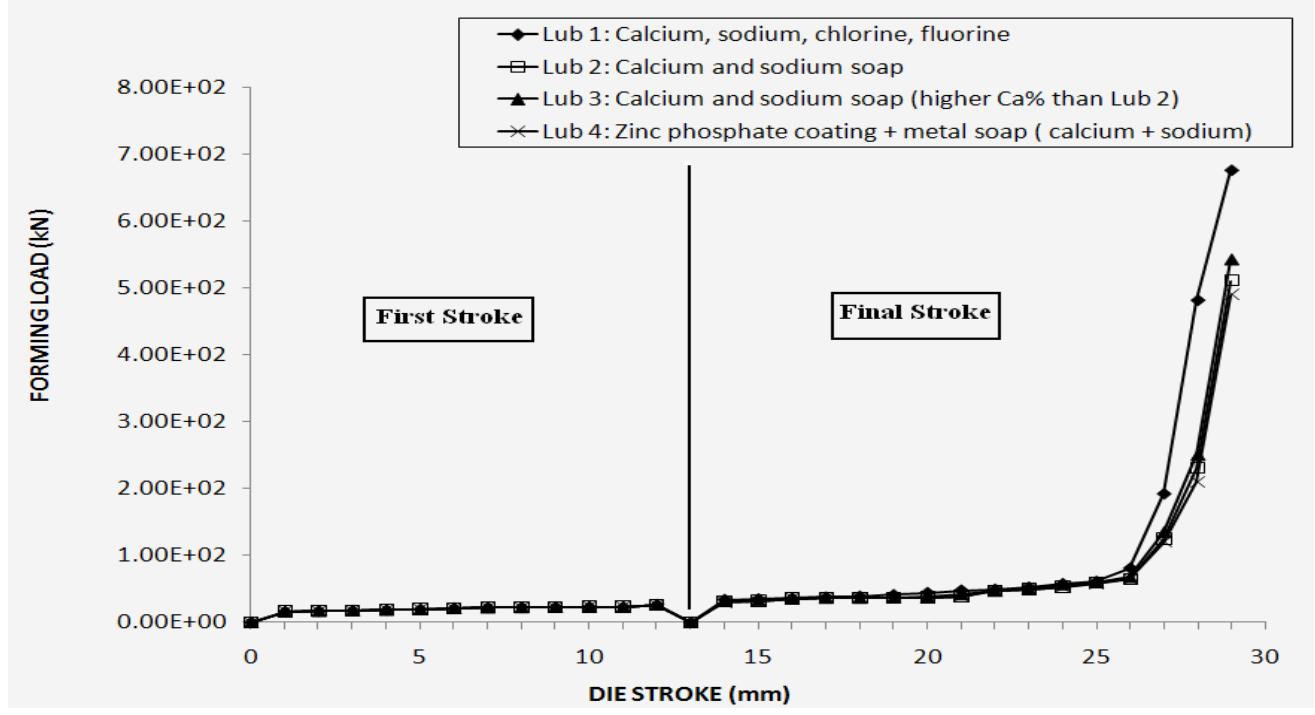

Figure 10. Forming load vs. die stroke curves for different types of lubricant.

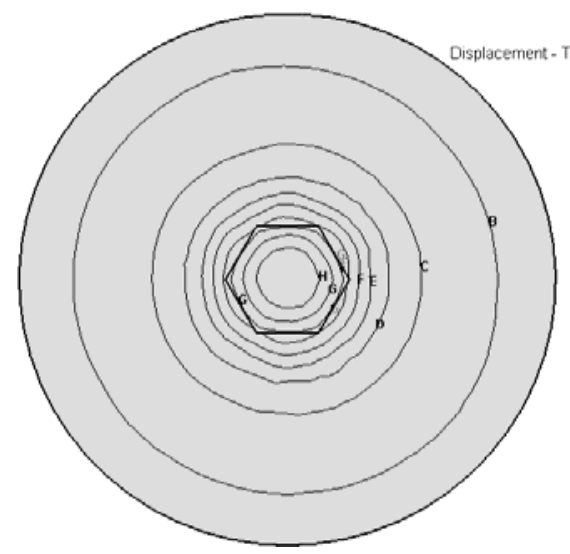

(a) Lub 1; maximum permanent $0.0860 \mathrm{~mm}$

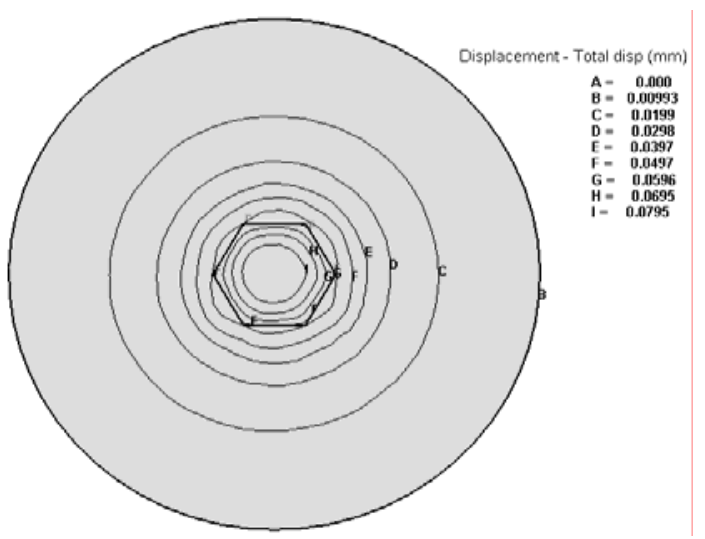

(c) Lub 3; maximum permanent displacement $=$ $0.0795 \mathrm{~mm}$

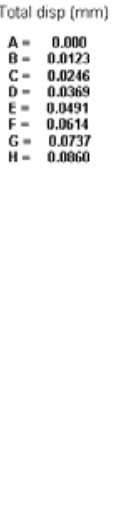

displacement $=$

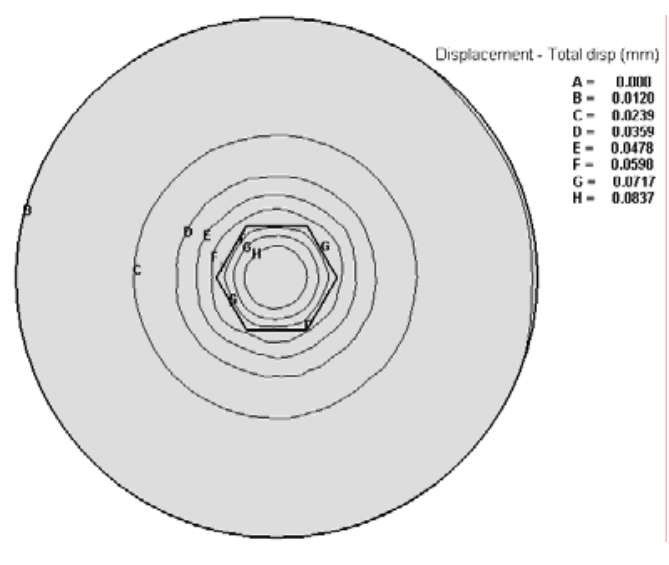

(b) Lub 2; maximum permanent displacement $=$ $0.0837 \mathrm{~mm}$

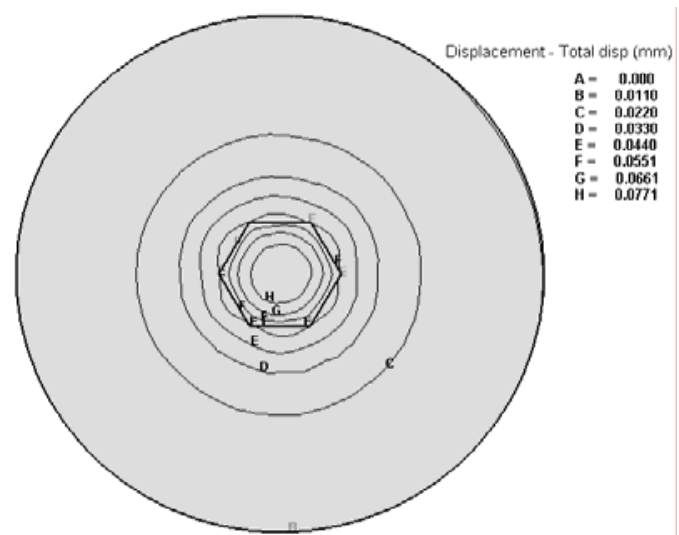

(d) Lub 4; maximum permanent displacement $=$ $0.0771 \mathrm{~mm}$

Figure 11. Tool permanent displacement at second punch evaluated by finite element method for different types of lubricant. 


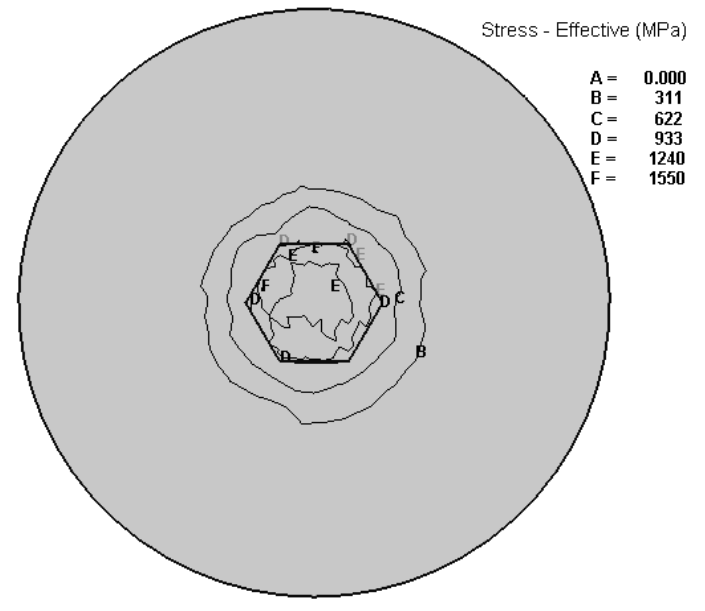

(a) Lub 1; maximum stress $=1550 \mathrm{MPa}$

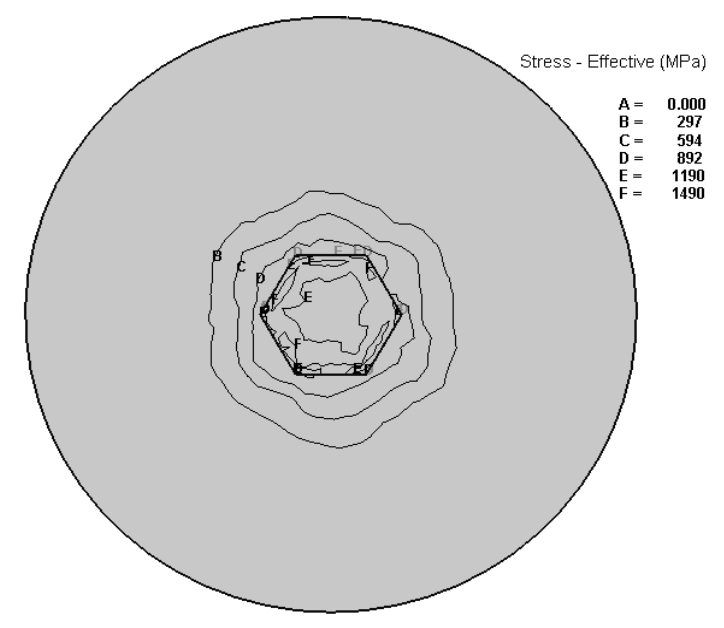

(c) Lub 3; maximum stress $=1490 \mathrm{MPa}$

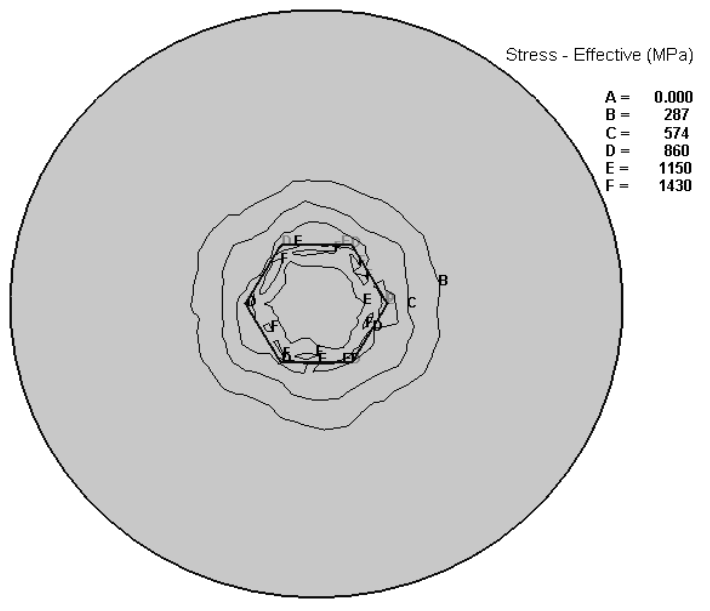

(b) Lub 2; maximum stress $=1430 \mathrm{MPa}$

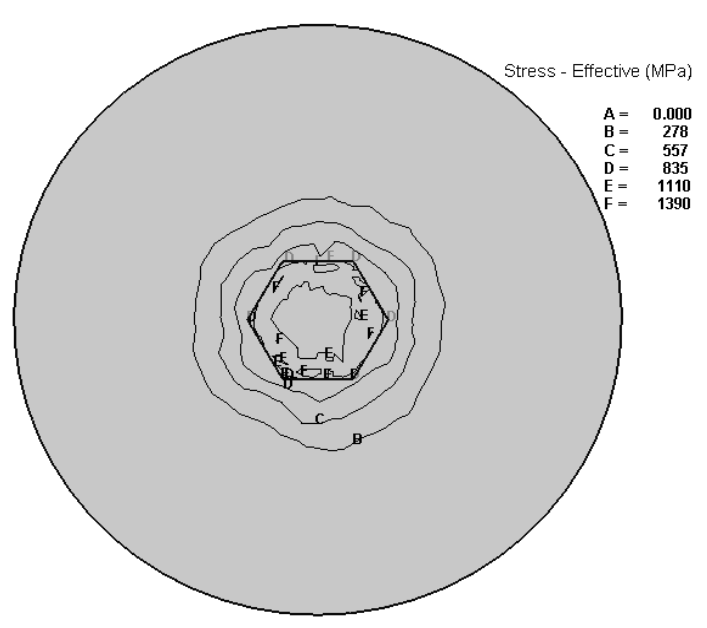

(d) Lub 4; maximum stress $=1390 \mathrm{MPa}$

Figure 12. Tool stress contour at second punch evaluated by finite element method for different types of lubricant. 